\title{
Rice Overexpressing OsNUC1-S Reveals Differential Gene Expression Leading to Yield Loss Reduction after Salt Stress at the Booting Stage
}

\author{
Chuthamas Boonchai ${ }^{1}$, Thanikarn Udomchalothorn ${ }^{1,2}$, Siriporn Sripinyowanich ${ }^{3}$, Luca Comai ${ }^{4}$, \\ Teerapong Buaboocha ${ }^{5,6}$ and Supachitra Chadchawan $1,6, *$ (D) \\ 1 Center of Excellence in Environment and Plant Physiology, Department of Botany, Faculty of Science, \\ Chulalongkorn University, Bangkok 10330, Thailand; Gwang_desu@hotmail.com (C.B.); \\ Thanikarn@sut.ac.th (T.U.) \\ 2 Surawiwat School, Suranaree University of Technology, Nakhon Ratchasima 30000, Thailand \\ 3 Faculty of Liberal Arts and Science, Kasetsart University, Kamphaeng Saen Campus, \\ Nakhon Pathom 73140, Thailand; wanich_s@hotmail.com \\ 4 Department of Plant Biology and Genome Center, University of California Davis, Davis, CA 95616, USA; \\ lcomai@ucdavis.edu \\ 5 Department of Biochemistry, Faculty of Science, Chulalongkorn University, Bangkok 10330, Thailand; \\ Teerapong.B@chula.ac.th \\ 6 Omics Science Center, Faculty of Science, Chulalongkorn University, Bangkok 10330, Thailand \\ * Correspondence: Supachitra.C@chula.ac.th or s_chadchawan@hotmail.com; Tel.: +66-2-2185485
}

Received: 17 November 2018; Accepted: 27 November 2018; Published: 7 December 2018

\begin{abstract}
Rice nucleolin (OsNUC1), consisting of two isoforms, OsNUC1-L and OsNUC1-S, is a multifunctional protein involved in salt-stress tolerance. Here, OsNUC1-S's function was investigated using transgenic rice lines overexpressing OsNUC1-S. Under non-stress conditions, the transgenic lines showed a lower yield, but higher net photosynthesis rates, stomatal conductance, and transpiration rates than wild type only in the second leaves, while in the flag leaves, these parameters were similar among the lines. However, under salt-stress conditions at the booting stage, the higher yields in transgenic lines were detected. Moreover, the gas exchange parameters of the transgenic lines were higher in both flag and second leaves, suggesting a role for OsNUC1-S overexpression in photosynthesis adaptation under salt-stress conditions. Moreover, the overexpression lines could maintain light-saturation points under salt-stress conditions, while a decrease in the light-saturation point owing to salt stress was found in wild type. Based on a transcriptome comparison between wild type and a transgenic line, after 3 and 9 days of salt stress, the significantly differentially expressed genes were enriched in the metabolic process of nucleic acid and macromolecule, photosynthesis, water transport, and cellular homeostasis processes, leading to the better performance of photosynthetic processes under salt-stress conditions at the booting stage.
\end{abstract}

Keywords: RNA binding protein; nucleolin; salt stress; photosynthesis; light saturation point; booting stage; transcriptome

\section{Introduction}

Rice (Oryza sativa L.) is a staple food and a main source of energy for humans, especially in Asia. There are several biotic or abiotic stresses that limit rice growth and yield, such as soil salinity, drought, and soil nutrition [1]. Salinity is a severe abiotic stress worldwide that directly contributes to the economic outcome of agriculturists. It negatively affects plants at both physiological and cellular levels. The plant water absorption is disrupted, leading to reductions in plant growth and development [2]. 
Moreover, ion toxicity also causes changes in plant metabolism, including the photosynthesis processes and energy production [3]. It directly affects photosynthetic components, including chlorophyll $a$, chlorophyll $b$, and carotenoids, because salt stress increases enzyme activities involved in chlorophyll degradation, which leads to a decrease in chlorophyll levels [4]. Moreover, it can also induce reactive oxygen species (ROS) production, which can trigger protein and lipid damage [5]. The level of plant injury depends on species, developmental stage, age, and also the severity of the salinity.

Rice is strongly affected by salt stress at both the seedling and reproductive stages [6]. These can remarkably affect rice plants that are grown in the paddy field of rain-fed areas containing rock salt underneath, like the northeastern region of Thailand [7], because rice is normally germinated at the beginning of the rainy season, when the salinity is low due to a certain amount of rain. However, when the land is drying from the evaporation due to the lack of rain, the salinity can migrate from the rock salt underneath through the surface [7], causing salt stress at the certain developmental stage of rice. If this occurs at the reproductive stage, it becomes the major effect for plant yield reduction [8].

Nucleolin, a multifunctional protein, is localized in various cellular locations, including the nucleus. It consists of three domains, the $\mathrm{N}$-terminus, containing several acidic stretches, the central region, containing an RNA-binding domain, and the C-terminus, containing a glycine/arginine-rich domain [9]. Because of differences in the numbers of each motif, different functions were found in different species. For example, the NUC-L1 gene in Arabidopsis thaliana is related to its growth and development [10], whereas in pea, this gene is regulated by light [11].

In rice, two forms of Nucleolin1 were found, a longer (OsNUC1-L, GenBank Accession No. AK103446) and a shorter (OsNUC1-S, GenBank Accession No. AK063918) form. OsNUC1-S lacks an $\mathrm{N}$-terminal region, but the cDNA sequences of the other regions are the same as the longer form. In 2013, Sripinyowanich and colleagues studied OsNUC1-S overexpression in Arabidopsis and found that this form promoted salt tolerance by increasing the number of lateral roots and enhancing root growth. In addition, the overexpression of this gene in rice leads to shoot fresh weight increasing when seedlings are grown under salt-stress conditions [12]. In the reproductive stage, the function of this gene is still unknown. Recently, the overexpression of the OsNUC1-L form resulted in an increase in salt tolerance in both rice and Arabidopsis by enhancing photosynthesis [13].

Here, we investigate the effects of OsNUC1-S overexpression on photosynthetic responses under normal and salt-stress conditions in transgenic rice at the reproductive stage and use a transcriptome analysis to explore the gene expression levels affected by OsNUC1-S overexpression. The experiments were performed in flag leaves and second leaves as both leaves have been reported to have a major role in generating carbohydrate resource from the photosynthesis process for seed production [14].

\section{Results}

\subsection{Overexpression of OSNUC1-S Affects Rice Yield}

The transgenic rice lines, TOSL1, TOSL2, and TOSL3, with OsNUC1-S overexpression were used in these experiments. OsNUC1 expression was compared among wild type (WT) and the transgenic lines, when grown in the control and salt stress condition at reproductive stage. Significantly higher OsNUC1 gene expression could be detected in transgenic lines when compared to WT, especially in the salt stress condition (Figure 1).

To investigate if the overexpression of OsNUC1-S affected rice productivity, the tiller number per plant, panicle number per plant, panicle length, fertility rate (\%), and seed number per plant of the transgenic rice, TOSL1, TOSL2, TOSL3, and WT, were evaluated as shown in Table 1. In the normal grown condition (control), over-expression of OsNUC1-S caused the reduction in \% fertility, leading to the reduction in seed number per plant. However, under salt stress, the transgenic lines tended to have the higher tiller number per plant, panicle number per plant, panicle length, \% fertility, and seed number per plant, except the TOSL2 line that showed similar $\%$ fertility and seed number per plant to WT. The reduction percentage of seeds/plants in WT was $64 \%$, while the transgenic lines had the 
seeds/plant reduction of $17 \%, 47 \%$, and $27 \%$. These data suggested that there should be some changes in metabolisms in the transgenic lines due to OsNUC1-S over-expression.

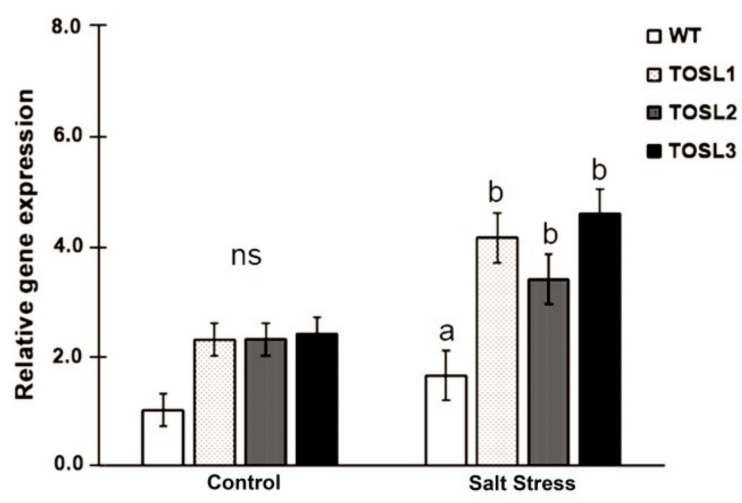

Figure 1. OsNUC1 gene expression in wild type (WT) and OsNUC1-S over-expression lines, TOSL1, TOSL2, and TOSL3, in the control and salt stress condition. Analysis of variance was performed and means were compared with Tukey's range test analysis. The data were presented as the mean $\pm \mathrm{SE}$ and a different letter above the bar showed the significant difference in means $(p<0.05)$. ns represents no statistically difference among means.

Table 1. Effects of salt stress at reproductive stage on tiller number per plant, panicle number per plant, panicle length, \% fertility, and seed number per plant.

\begin{tabular}{ccccccccc}
\hline \multirow{2}{*}{$\begin{array}{c}\text { Reproductive } \\
\text { Characters }\end{array}$} & \multicolumn{9}{c}{ Control $^{*}$} \\
\cline { 2 - 8 } & WT & TOSL1 & TOSL2 & TOSL3 & WT & TOSL1 & TOSL2 & TOSL3 \\
\hline \multirow{2}{*}{ Tiller number/pl } & $5.75 \pm$ & $5.25 \pm$ & $7.00 \pm$ & $5.50 \pm$ & $3.00 \pm$ & $3.75 \pm$ & $4.50 \pm$ & $4.00 \pm$ \\
& $0.55^{\mathrm{ab}}$ & $0.55^{\mathrm{abc}}$ & $0.55^{\mathrm{a}}$ & $0.55^{\mathrm{abc}}$ & $0.55^{\mathrm{c}}$ & $0.55^{\mathrm{bc}}$ & $0.555^{\mathrm{abc}}$ & $0.55^{\mathrm{bc}}$ \\
\hline \multirow{2}{*}{ Panicle number/pl } & $5.25 \pm$ & $3.50 \pm$ & $3.50 \pm$ & $3.00 \pm$ & $1.75 \pm$ & $2.50 \pm$ & $2.75 \pm$ & $2.00 \pm$ \\
& $0.33^{\mathrm{a}}$ & $0.33^{\mathrm{b}}$ & $0.33^{\mathrm{b}}$ & $0.33^{\mathrm{bc}}$ & $0.33^{\mathrm{c}}$ & $0.33^{\mathrm{bc}}$ & $0.33^{\mathrm{bc}}$ & $0.33^{\mathrm{bc}}$ \\
\hline \multirow{2}{*}{ Panicle length } & $10.15 \pm$ & $9.28 \pm$ & $8.87 \pm$ & $8.87 \pm$ & $7.38 \pm$ & $8.27 \pm$ & $9.00 \pm$ & $9.73 \pm$ \\
& 0.71 & 0.71 & 0.71 & 0.71 & 0.71 & 0.71 & 0.71 & 0.71 \\
\hline \multirow{2}{*}{$\%$ Fertility } & $65.36 \pm$ & $45.18 \pm$ & $48.39 \pm$ & $44.34 \pm$ & $15.27 \pm$ & $47.03 \pm$ & $14.17 \pm$ & $36.84 \pm$ \\
& $9.52^{\mathrm{a}}$ & $9.52^{\mathrm{ab}}$ & $9.52^{\mathrm{ab}}$ & $9.52^{\mathrm{ab}}$ & $9.52^{\mathrm{b}}$ & $9.52^{\mathrm{ab}}$ & $9.52^{\mathrm{b}}$ & $9.52^{\mathrm{ab}}$ \\
\hline \multirow{2}{*}{ Seeds per plant } & $193.50 \pm$ & $108.75 \pm$ & $130.00 \pm$ & $115.75 \pm$ & $70.25 \pm$ & $89.75 \pm$ & $68.50 \pm$ & $84.50 \pm$ \\
& $11.15^{\mathrm{a}}$ & $11.15^{\mathrm{bc}}$ & $11.15^{\mathrm{b}}$ & $11.15^{\mathrm{bc}}$ & $11.15^{\mathrm{c}}$ & $11.15^{\mathrm{bc}}$ & $11.15^{\mathrm{c}}$ & $11.15^{\mathrm{bc}}$ \\
\hline
\end{tabular}

* The experiment was performed with random complete block design in four replicates, each of which consisted of two individuals. Analysis of variance was performed and means were compared with Tukey's range test analysis. The data were presented as the mean $\pm \mathrm{SE}$ and a different letter above the bar showed the significant difference in means $(p<0.05)$.

\subsection{Overexpression of OSNUC1-S Increased the Photosynthetic Rate, Stomatal Conductance, and Transpiration Rate under Salt-Stress Conditions}

Salt stress can cause a decrease in productivity in rice, and the major organs generating the carbohydrate for grain filling are flag leaves and second leaves. Therefore, we investigated the photosynthetic activities in both of these leaves in WT and OsNUC1-S over-expressing lines under control and salt stress conditions. Under the control condition, only second leaves of transgenic rice overexpressing OSNUC1-S showed higher net photosynthetic rates $\left(\mathrm{P}_{\mathrm{N}}\right)$ and stomatal conductance levels $\left(g_{s}\right)$, while the flag leaves had similar levels, except TOSL2, which had a lower $P_{N}$ than the other lines. These results may reflect positional effects of the transformation. After 9 days of salt stress, the overexpression of OsNUC1-S increased the $\mathrm{P}_{\mathrm{N}}$ and $\mathrm{g}_{\mathrm{s}}$ of all the transgenic lines (Figure 2). The $P_{N}$ values in flag leaves of transgenic plants were approximately two-fold those of the WT (Figure 2A), while in second leaves, the $\mathrm{P}_{\mathrm{N}}$ values of transgenic plants increased up to 2.5-fold those of WT (Figure 2B). Similar effects were also found for the $g_{s}$ values of both flag and second leaves 
(Figure 2C,D). There was no effect on the intercellular $\mathrm{CO}_{2}$ concentration (Ci) (Figure 2E,F), but OsNUC1-S's overexpression resulted in an increased transpiration rate of the second leaves under control conditions and in the flag leaves under salt-stress conditions (Figure 2G,H).

A

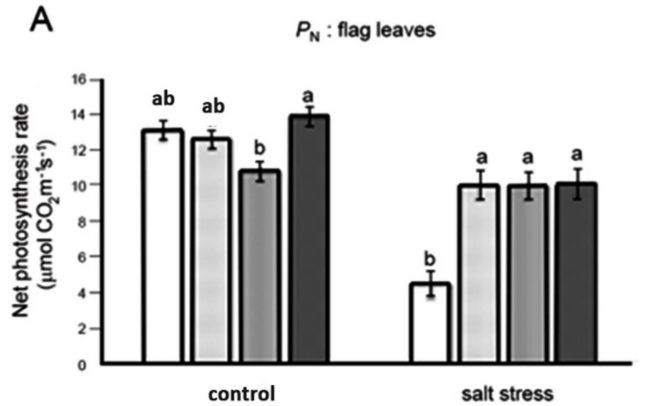

C
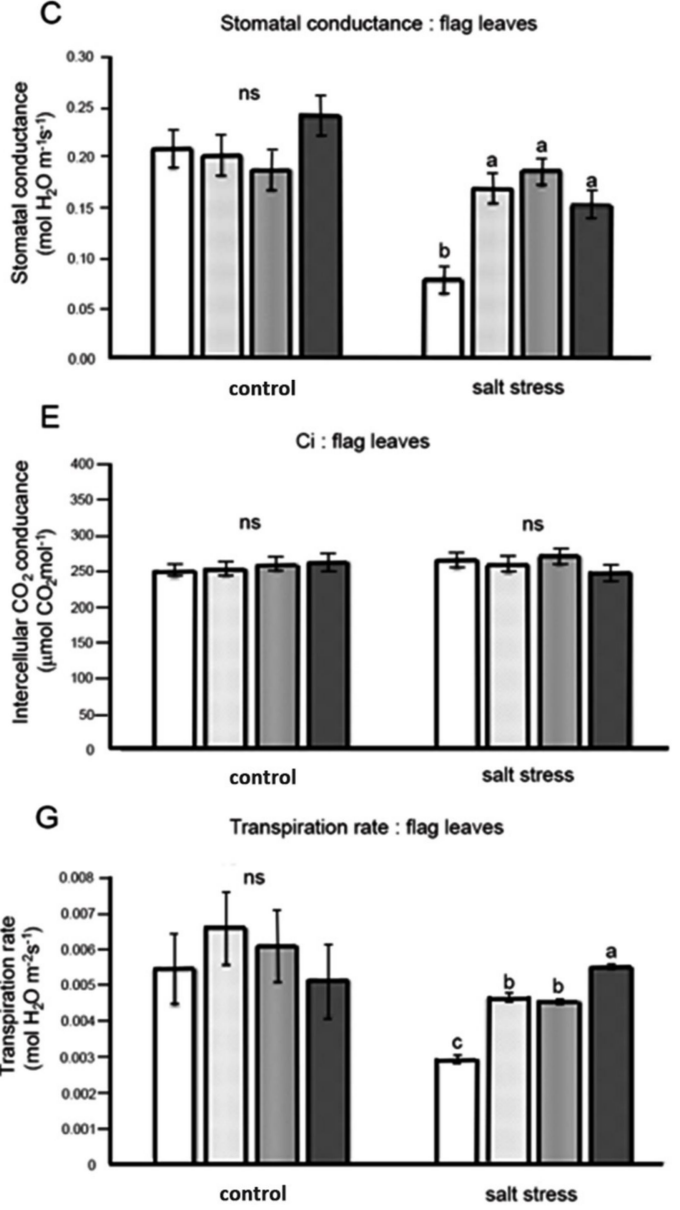
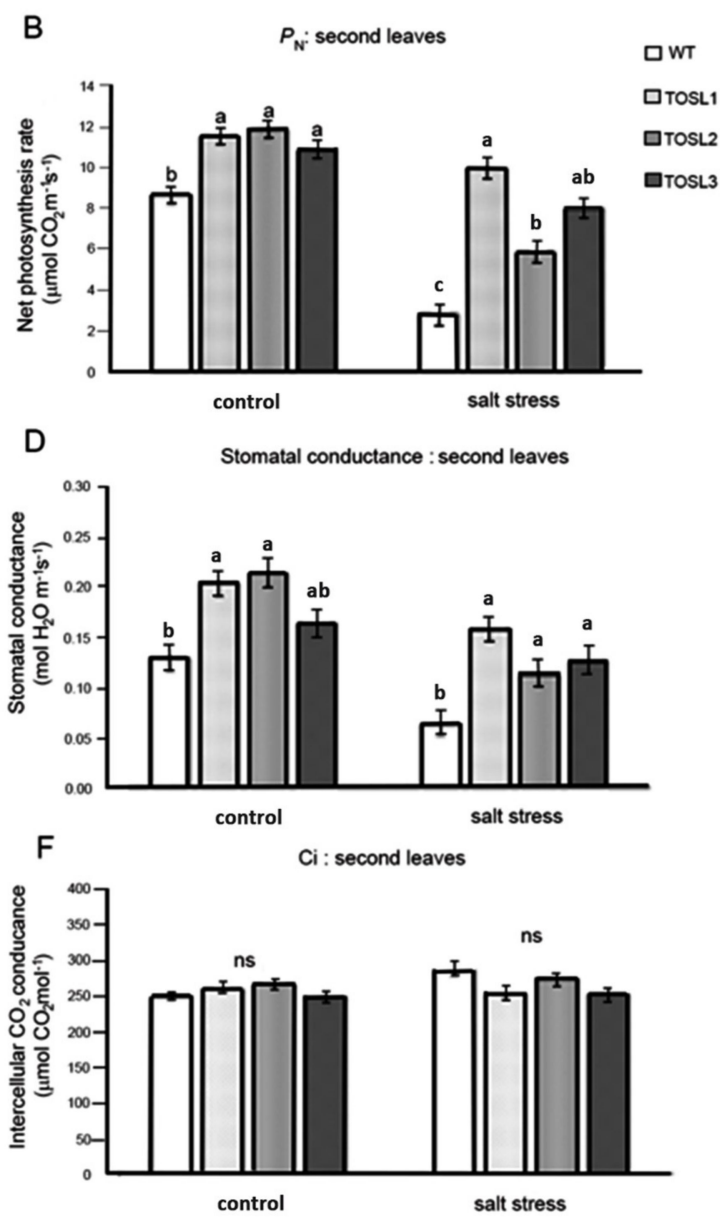

$\mathrm{H}$

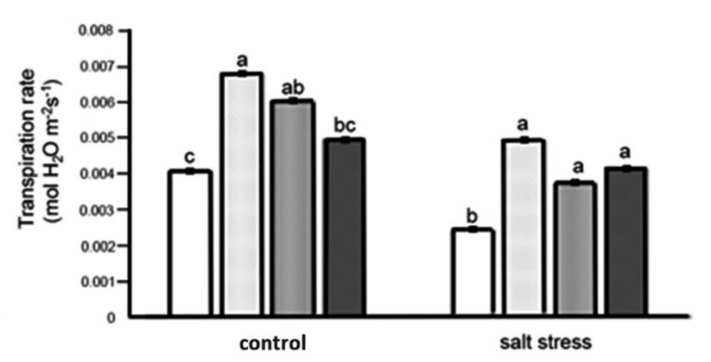

Figure 2. The net photosynthetic rate $\left(\mathrm{P}_{\mathrm{N}}\right)(\mathbf{A}, \mathbf{B})$, stomatal conductance $\left(\mathrm{g}_{\mathrm{s}}\right)(\mathbf{C}, \mathbf{D})$, intercellular $\mathrm{CO}_{2}$ concentration $(\mathrm{Ci})(\mathbf{E}, \mathbf{F})$, and transpiration rate $(E)(\mathbf{G}, \mathbf{H})$ of flag leaves $(\mathbf{A}, \mathbf{C}, \mathbf{E}, \mathbf{G})$ and second leaves $(\mathbf{B}, \mathbf{D}, \mathbf{F}, \mathbf{H})$, when wild type (WT) and the OsNUC1-S overexpressing lines, TOSL1, TOSL2, and TOSL3, were grown under control or salt-stress conditions. The data were presented as the mean $\pm \mathrm{SE}$ and a different letter above the bar showed the significant difference in means $(p<0.05)$ based on Tukey's range test analysis. ns represents no statistically difference among means.

\subsection{Overexpression of OSNUC1-S Affected Both Light-Response Curves and $\mathrm{CO}_{2}$-Response Curves of Flag and Second Leaves under Salt-Stress Conditions}

We investigated the light-response curves of these lines. The light-response curves of the flag leaves in all the lines were similar when the light intensity varied from 100 to $2000 \mu \mathrm{mol} \cdot \mathrm{m}^{-2} \cdot \mathrm{s}^{-1}$, except TOSL2, which had a lower $\mathrm{P}_{\mathrm{N}}$ than other lines. The light-saturation points were approximately 
$1000 \mu \mathrm{mol} \cdot \mathrm{m}^{-2} \cdot \mathrm{s}^{-1}$ in all lines (Figure $3 \mathrm{~A}$ ). The salt stress caused decreases in the $\mathrm{P}_{\mathrm{N}}$ values of all the lines, but the transgenic lines had significantly higher $\mathrm{P}_{\mathrm{N}}$ values when the light intensity was greater than $200 \mu \mathrm{mol} \cdot \mathrm{m}^{-2} \cdot \mathrm{s}^{-1}$. The light-saturation point of the WT decreased to $600 \mu \mathrm{mol} \cdot \mathrm{m}^{-2} \cdot \mathrm{s}^{-1}$, while the transgenic lines had light-saturation points similar to those of plants grown under control conditions $\left(1000 \mu \mathrm{mol} \cdot \mathrm{m}^{-2} \cdot \mathrm{s}^{-1}\right)$ (Figure 3B).
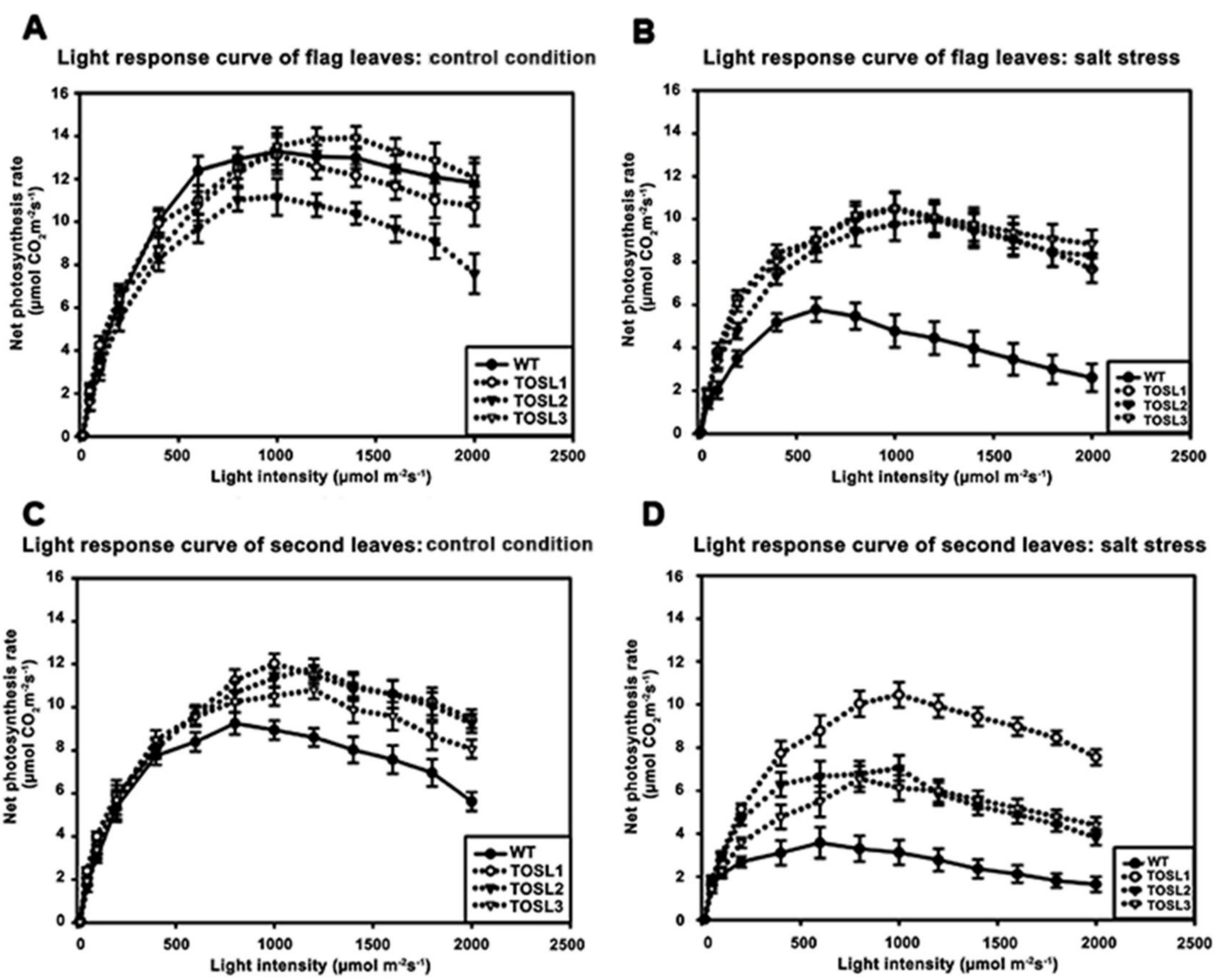

\section{D}

Light response curve of second leaves: salt stress

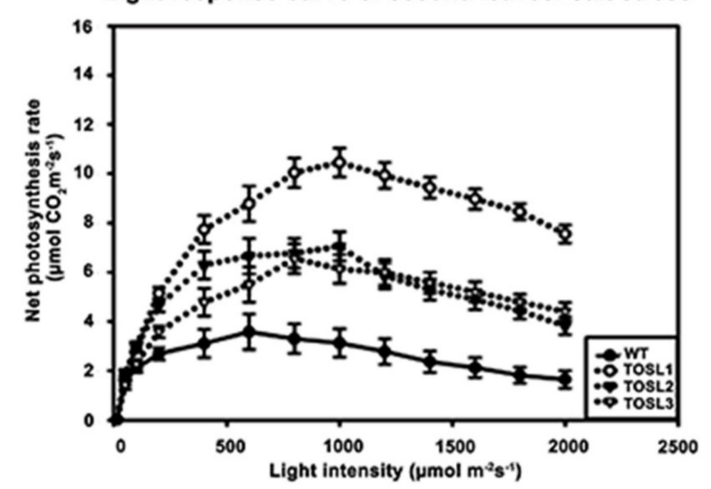

Figure 3. Light-response curves of flag leaves $(\mathbf{A}, \mathbf{B})$ and second leaves $(\mathbf{C}, \mathbf{D})$, when wild type and transgenic lines, TOSL1, TOSL2, and TOSL3, were grown under control $(\mathbf{A}, \mathbf{C})$ and salt-stress (B,D) conditions.

The second leaves of the WT had lower light-saturation points than those of the transgenic lines when grown under control conditions. The $\mathrm{P}_{\mathrm{N}}$ values of the $\mathrm{WT}^{\prime} \mathrm{s}$ second leaves started to decline when the light intensity was greater than $800 \mu \mathrm{mol} \cdot \mathrm{m}^{-2} \cdot \mathrm{s}^{-1}$; however, for the transgenic lines, the light-saturation point was $1000 \mu \mathrm{mol} \cdot \mathrm{m}^{-2} \cdot \mathrm{s}^{-1}$ (Figure 3C).

Salt stress caused a decrease in the light-saturation point in WT second leaves, but it did not affect the light-saturation points of the transgenic lines' second leaves. In WT second leaves, the light-saturation point declined to $600 \mu \mathrm{mol} \cdot \mathrm{m}^{-2} \cdot \mathrm{s}^{-1}$, and a more than two-fold reduction in the $\mathrm{P}_{\mathrm{N}}$ was found. A similar reduction in the $\mathrm{P}_{\mathrm{N}}$ was found in the transgenic lines, except TOSL1, which maintained a $P_{N}$ in its second leaves that was similar to the $P_{N}$ under control growth conditions. However, all the transgenic lines' second leaves had light-saturation points of $1000 \mu \mathrm{mol} \cdot \mathrm{m}^{-2} \cdot \mathrm{s}^{-1}$ (Figure 3D).

The $\mathrm{CO}_{2}$-response curves of flag and second leaves of all the lines were also investigated as the $\mathrm{CO}_{2}$ concentration increased from 200 to $1000 \mu \mathrm{mol} \cdot \mathrm{mol}^{-1}$. Under control conditions, the flag leaves of all the lines showed similar $\mathrm{CO}_{2}$-response curves. The $\mathrm{CO}_{2}$-saturation point was $\sim 800 \mu \mathrm{mol} \cdot \mathrm{mol}^{-1}$ (Figure 4A). Under salt-stress conditions, significantly higher $\mathrm{P}_{\mathrm{N}}$ values of the flag leaves were found in all the transgenic lines when the $\mathrm{CO}_{2}$ concentration was greater than $200 \mu \mathrm{mol} \cdot \mathrm{mol}^{-1}$. However, salt stress had no effect on the $\mathrm{CO}_{2}$-saturation points of flag leaves in any line (Figure 4B). 
A $\mathrm{CO}_{2}$ response curve of flag leaves: control condition

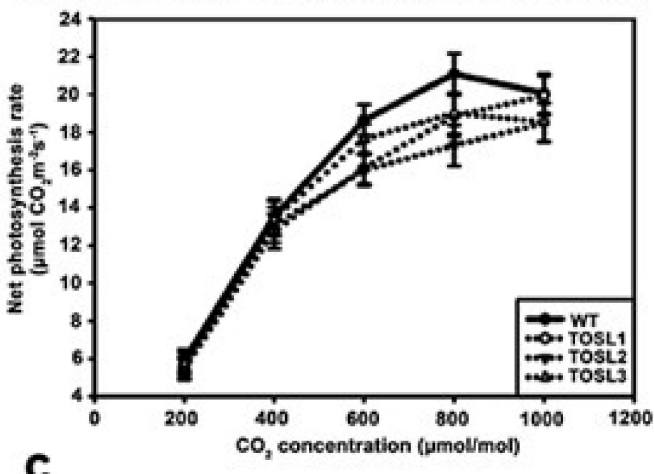

C

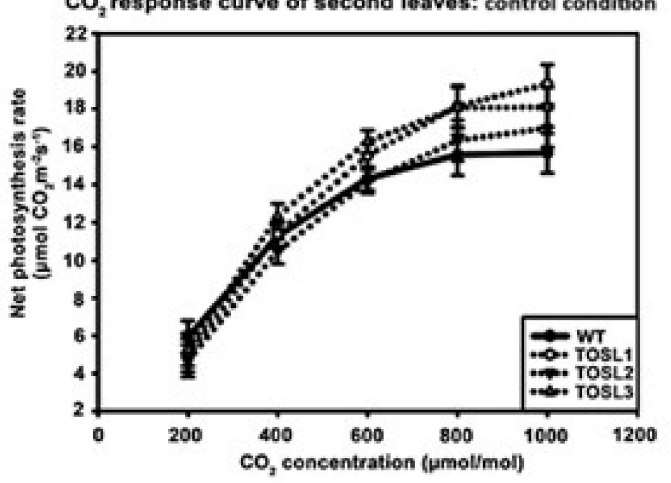

B $\mathrm{CO}_{2}$ response curve of flag leaves: salt stress

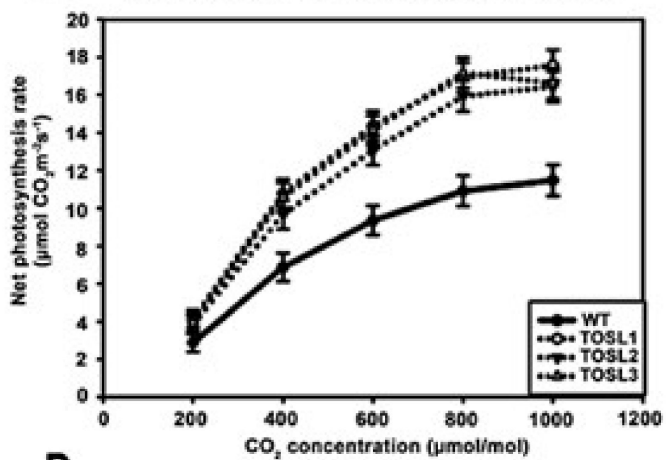

D

$\mathrm{CO}_{2}$ response curve of second leaves: salt stress

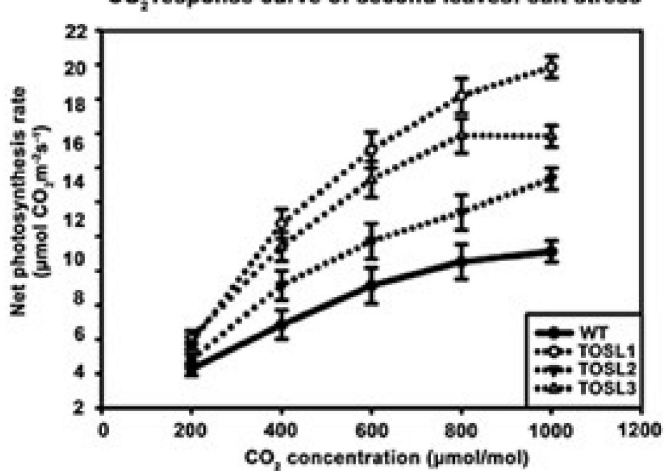

Figure 4. $\mathrm{CO}_{2}$-response curves of flag leaves $(\mathbf{A}, \mathbf{B})$ and second leaves $(\mathbf{C}, \mathbf{D})$, when wild type and transgenic lines, TOSL1, TOSL2, and TOSL3, were grown under control $(\mathbf{A}, \mathbf{C})$ and salt-stress (B,D) conditions.

In the second leaves, the $\mathrm{CO}_{2}$-response curves and $\mathrm{CO}_{2}$-saturation points of all the lines were similar and consistent with the flag leaf's response to the lower $P_{\mathrm{N}}$ in plants grown under control conditions (Figure 4C). Salt stress caused decreases in the $P_{N}$ values of all the lines, but it did not affect the $\mathrm{CO}_{2}$ saturation point of WT second leaves. On the contrary, TOSL1 and TOSL2's second leaves had increased $\mathrm{CO}_{2}$ saturation points to over $1000 \mathrm{mmol} \cdot \mathrm{mol}^{-1}$, while TOSL3 showed the same $\mathrm{CO}_{2}$ saturation point as WT second leaves, when grown under salt-stress conditions (Figure 4D).

\subsection{Salt Stress Affects Photosystem II (PSII) Photochemistry Efficiency and Photosynthetic Pigment Contents in Flag and Second Leaves}

To investigate the effect of salt stress on the efficiency of PSII photochemistry, the $F_{v} / F_{m}$ ratio was investigated. The salt-stress level did not significantly affect the PSII efficiency in the flag leaves of any lines (Figure 5A). However, in the second leaves, a significant reduction in the PSII efficiency $\left(\mathrm{F}_{\mathrm{v}} / \mathrm{F}_{\mathrm{m}}\right)$ was found in WT after 9 days of salt treatment, while in all the transgenic lines, a reduced effect was found (Figure 5B). Thus, second leaves were more susceptible to salt stress than flag leaves, and OsNUC1-S's overexpression contributed to the PSII photochemistry efficiency under salt-stress conditions. 


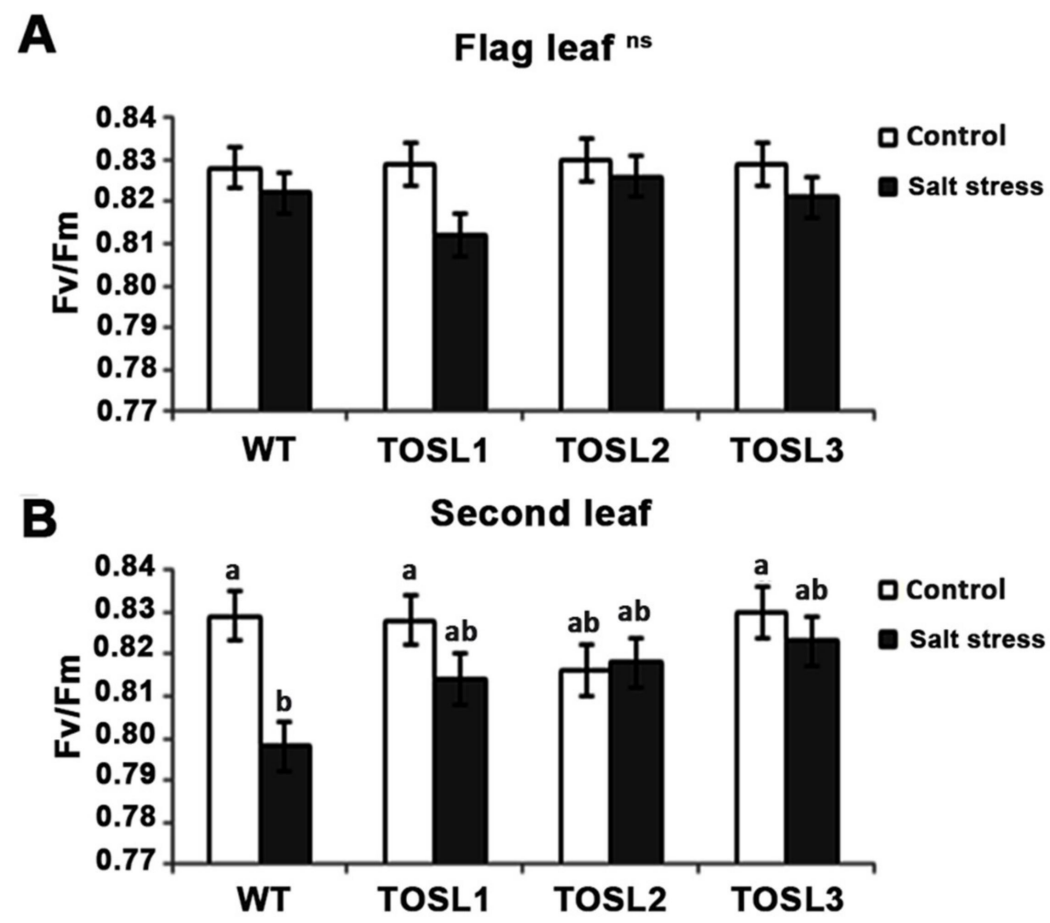

Figure 5. The $\mathrm{F}_{\mathrm{v}} / \mathrm{F}_{\mathrm{m}}$ ratios of flag leaves $(\mathbf{A})$ and second leaves $(\mathbf{B})$ under control conditions and after being treated with $150 \mathrm{mM} \mathrm{NaCl}$ solution for 9 days. Three independent OsNUC1-S transgenic rice lines with difference transgene expression levels and WT plants were used. The data were presented as the mean \pm SE and a different letter above the bar showed the significant difference in means $(p<0.05)$ based on Tukey's range test analysis. ns represents no statistically difference among means.

OsNUC1-S's overexpression tended to increase both the chlorophyll and carotenoid contents in flag leaves, but not in the second leaves, under optimal growth conditions (Figure 6A-F). Salt stress caused decreases in all of the pigments in the flag leaves, but significantly higher carotenoid contents were found in both flag and second leaves in the transgenic lines when compared with WT (Figure 6E,F).

\subsection{OsNUC1-S's Overexpression Increased Carbohydrate Metabolism and Sugar Transport in Flag Leaves of Rice Grown Under Control Conditions}

Because of the effects of OsNUC1-S's overexpression on the photosynthetic characteristics, the transcriptome approach was used to investigate changes at the transcript level. TOSL3 was chosen as the representative for investigations of the flag leaf transcriptome. Based on a transcriptome comparison of DEGs (differentially expressed genes) between WT and TOSL3, when grown under control conditions, the DEGs were highly enriched in the cellular macromolecule metabolic processes, including the macromolecule biosynthetic process. Genes involved in transmembrane transport, regulation of cellular process, and the pigment metabolic process were also found. 
A

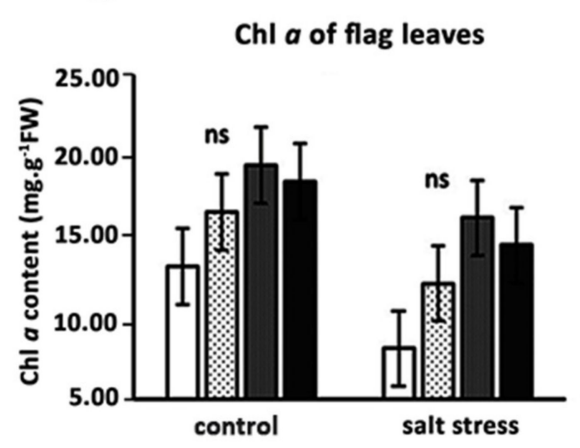

C

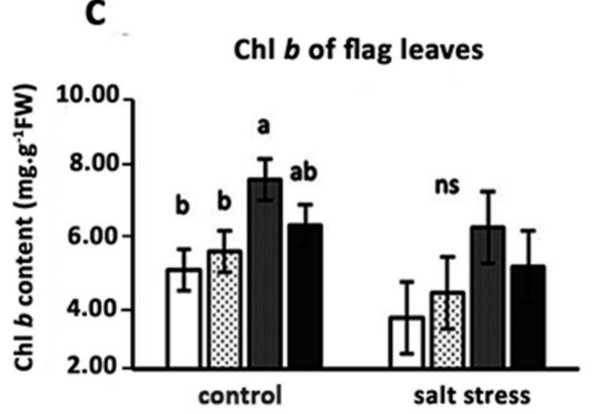

$\mathbf{E}$

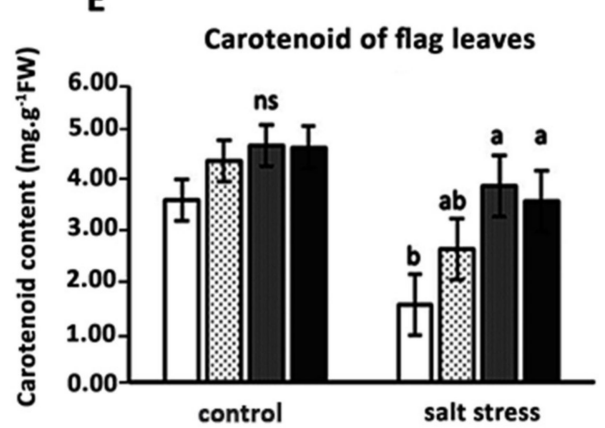

B

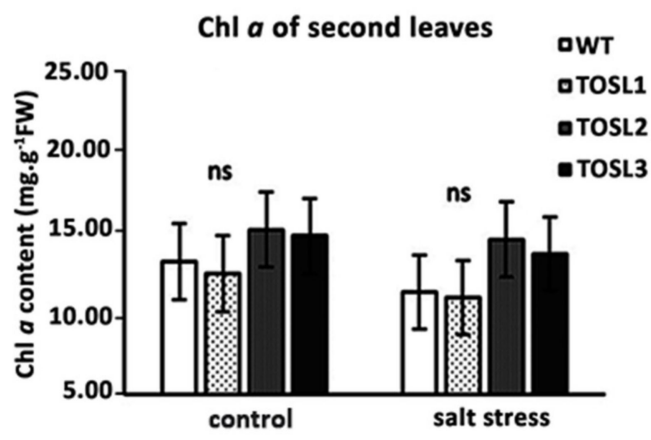

D

$\mathrm{Chl} b$ of second leaves

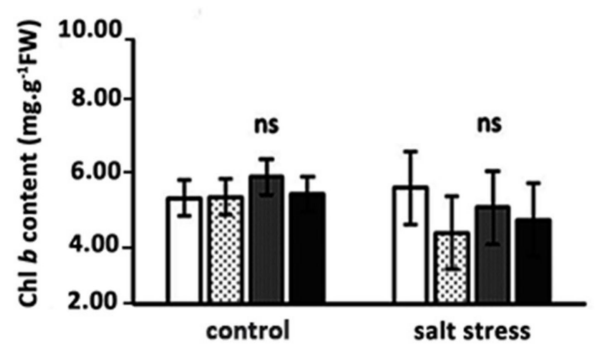

$\mathbf{F}$

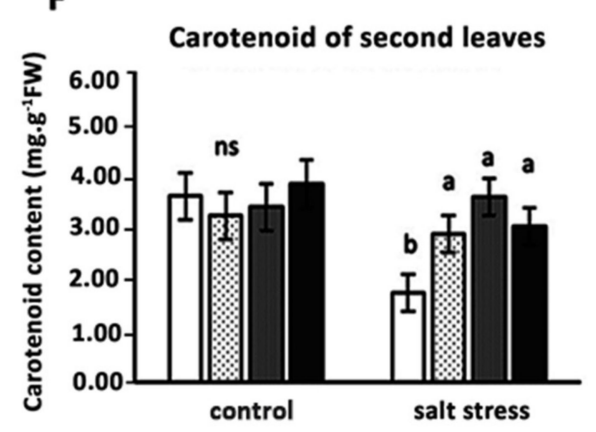

Figure 6. Photosynthetic pigments in flag leaves $(\mathbf{A}, \mathbf{C}, \mathbf{E})$ and second leaves $(\mathbf{B}, \mathbf{D}, \mathbf{F}) 9$ days after the salt-stress treatment at the booting stage. The data were presented as the mean $\pm \mathrm{SE}$ and a different letter above the bar showed the significant difference in means $(p<0.05)$ based on Tukey's range test analysis. ns represents no statistically significant difference among means.

For the cellular component enrichment, a plasma membrane and chloroplast envelope were reported. This supported OsNUC1-S's role in the enhancement of macromolecule production for grain filling in the flag leaves. Interestingly, the molecular function enrichment was found for only linoleate 13S-lipoxygenase activity. This enzyme is involved in plant growth and development [15], and also in the wounding response through jasmonic acid (JA) signaling [16,17] (Figure 7A).

Six days later, the DEGs resulting from OsNUC1-S expression changed. For the biological process, the genes functioning in carbohydrate transport were enriched, supporting the role of flag leaves in seed development. The consistent enrichment of molecular function in substrate-specific transmembrane transport was found (Figure 7B). 
A
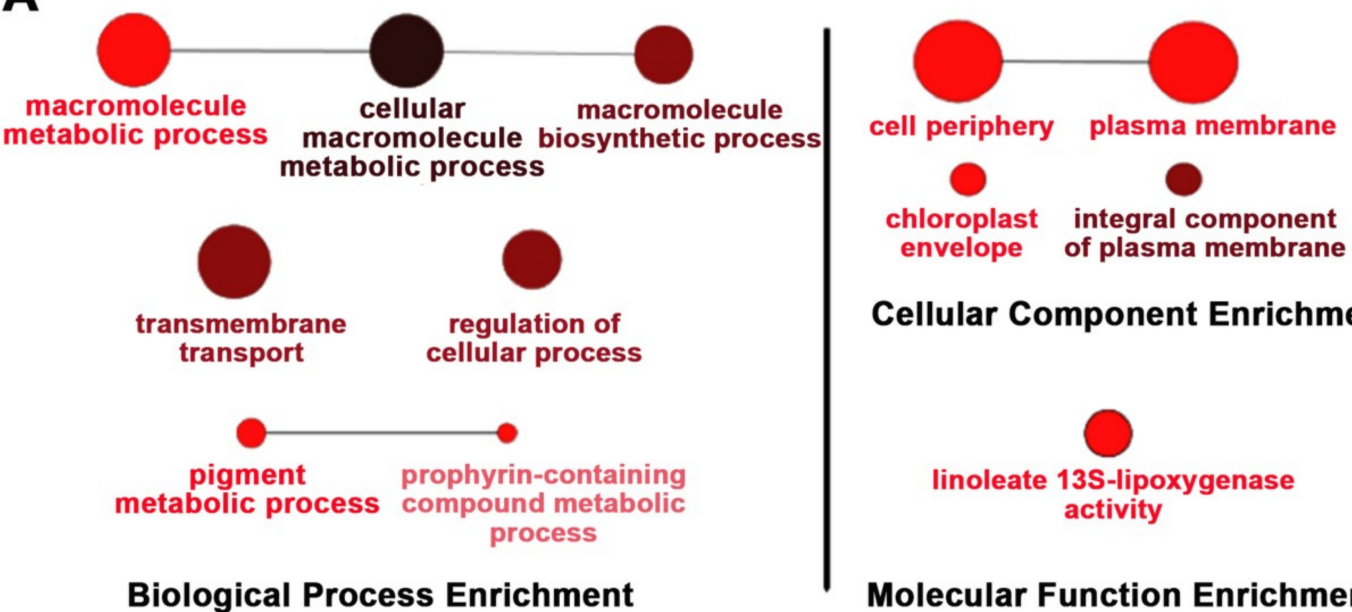

Cellular Component Enrichment

B

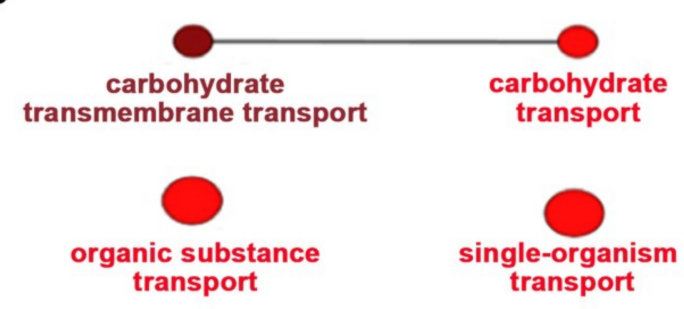

Biological Process Enrichment

substrate-specific

transmembrane

transporter activity

\section{Molecular Function Enrichment}

Figure 7. Gene enrichment analysis of the differentially expressed genes in the TOSL3 line, which overexpresses OsNUC1-S. The tissues for the transcriptome analysis were collected 3 days (A) and 9 days (B) after the first day of the booting stage. The darker colors represent the higher significance and the larger size of node represents the higher number of genes in the group.

2.6. The Overexpression of OsNUC1-S Increased the Expression of Genes Involved in Water Transport and Cellular Homeostasis, Nucleic Acid and Macromolecule Metabolic Processes, and Photosynthetic Processes

Under salt-stress conditions, the effects of OsNUC1-S overexpression were different from the effects found in normally grown plants. After 3 days of salt stress, the flag leaves of the transgenic lines were enriched with transcripts of genes involved in water transport and cellular homeostasis, nucleic and macromolecule metabolic processes, and photosynthetic processes. This was also consistent with the cellular enrichment in chloroplasts and nuclei. For the KEGG pathways, enrichment occurred in photosynthesis, carbon fixation, porphyrin and chlorophyll metabolism, and carotenoid biosynthesis, all of which involved activities in chloroplasts. Moreover, genes in glyoxylate and dicarboxylate metabolism, and terpenoid backbone biosynthesis, were also enriched (Figure 8). 


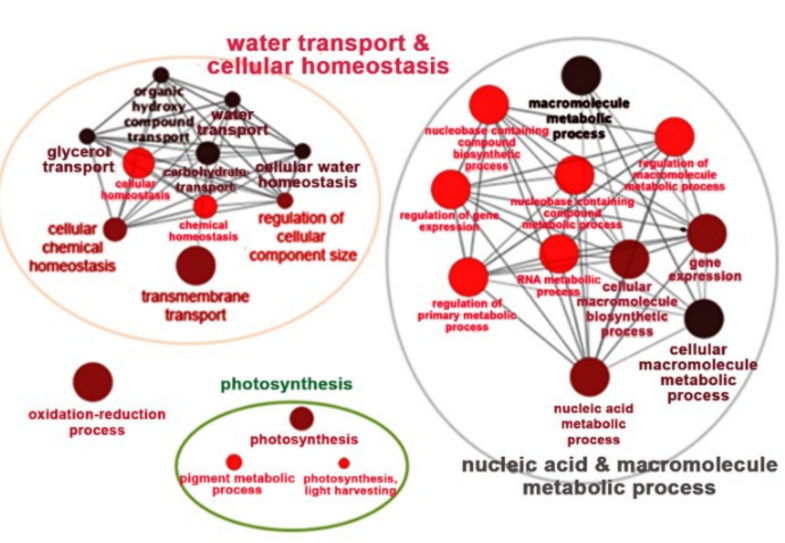

Biological Process Enrichment

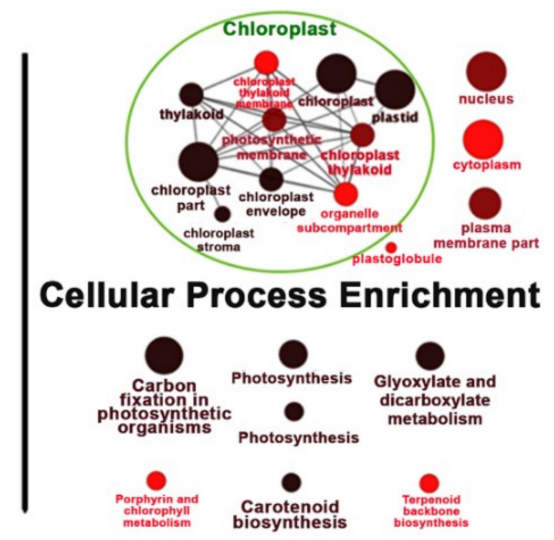

KEGG Pathway Enrichment

Figure 8. The enrichment for the biological process, cellular process, and Kyoto Encyclopedia of Genes and Genomes (KEGG) pathways of the differentially expressed genes in the flag leaves of transgenic rice overexpressing OsNUC1-S after 3 days of salt stress. The darker colors represent the higher significance and the larger size of node represents the higher number of genes in the group.

When the plants were under a prolonged stress for 9 days, similar processes, cellular compartments, and metabolic pathways were found to be affected, except that pigment and porphyrin-containing compound metabolic processes were detected, suggesting more pigment synthesis-related processes occurred, while the enrichment in light harvesting was not found. A new set of enriched genes found at this time point was in carboxylic acid metabolic processes and responses to oxidative stress. Chloroplasts were the main organelles that were enriched with the transcripts of genes affected by OsNUC1-S expression. The enrichment of the genes in the nucleus and plasma membrane also had a similar pattern to that found in flag leaves after 3 days of salt stress. The pathway enrichment after salt stress for 9 days was similar to that found after 3 days of stress, with more pathways in amino sugar and nucleotide sugar metabolism, pyruvate metabolism, ascorbate and aldarate metabolism, and pentose phosphate pathways (Figure 9). The list of the differentially expressed genes between wild type and transgenic rice with OsNUC1-S overexpression after salt stress treatment for 3 and 9 days is shown in Supplementary Table S1.

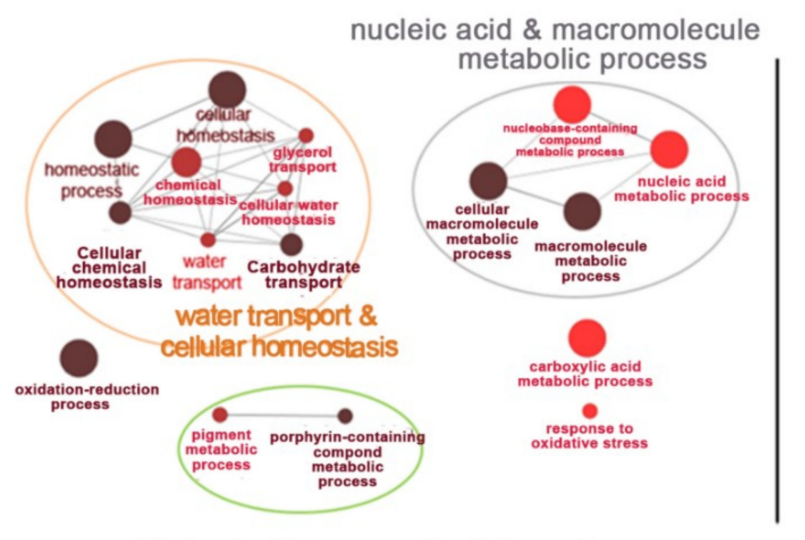

Biological Process Enrichment

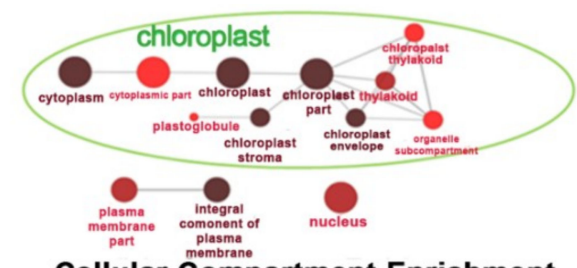

Cellular Compartment Enrichment

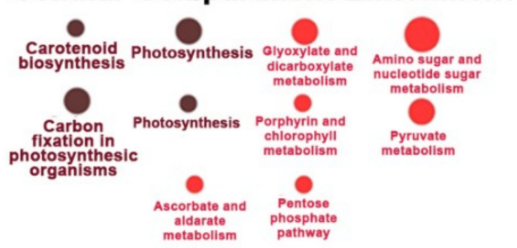

KEGG Pathway Enrichment

Figure 9. The enrichment for biological process, cellular process, and KEGG pathways of the differentially expressed genes in the flag leaves of transgenic rice overexpressing OsNUC1-S after 9 days of salt stress. The darker colors represent the higher significance and the larger size of the node represents the higher number of genes in the group. 
To validate the RNA-Seq data, the up-regulated genes after 3 days of salt stress, LOC_Os01g58470 (CEST) (Figure 10A), LOC_Os03g39610 (CAB) (Figure 10B), and LOC_Os04g33830 (PSAO) (Figure 10C), were chosen as representatives for quantitative RT-PCR (qRT-PCR). The expression in the transgenic line, TOSL3 was about two- to three-fold higher than WT under salt stress condition, based on RNA-Seq analysis (Supplementary Table S1). The comparable expression was also detected by qRT-PCR as shown in Figure 10A-C. Based on RNA-Seq analysis, LOC_Os01g64960 (PsbS1) (Figure 10D) showed the highest fold change when compared to WT after salt stress for 9 days. The qRT-PCR of this gene expression revealed about five-fold higher expression than WT after 9 days (Figure 10D). The increase in the expression of these genes was correlated with the RNA-Seq data.

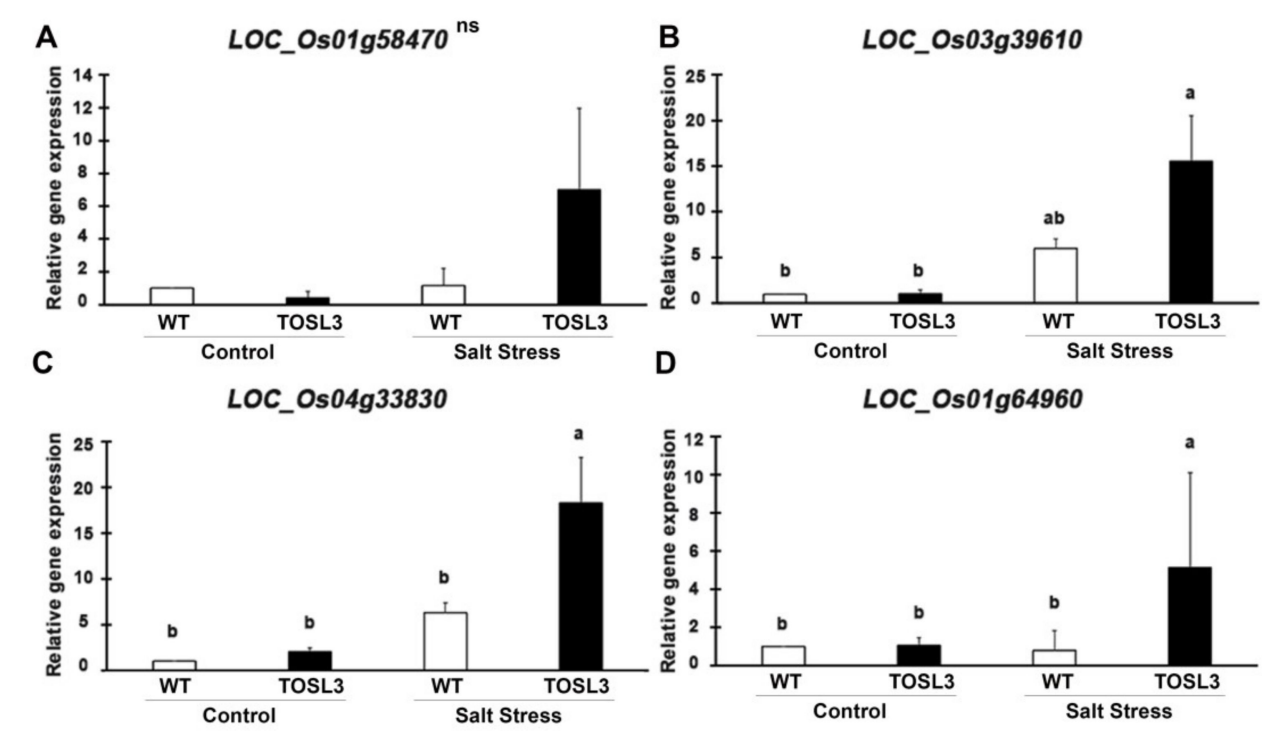

Figure 10. Gene expression analysis of LOC_Os01g58470 (A), LOC_Os03g39610 (B), LOC_Os04g33830 (C), and LOC_Os01g64960 (D) in WT and TOSL3 plants under control and salt stress conditions. Bar represents standard deviation of three biological replicates. The measurement was performed with three technical replicates. The data were presented as the mean $\pm \mathrm{SE}$ and a different letter above the bar showed the significant difference in means $(p<0.05)$ based on Tukey's range test analysis. ns represents no statistically significant difference among means.

\section{Discussion}

OsNUC1-S, one of the mRNA splice forms, lacks an N-terminal region that contains several acidic stretches and a nuclear localization signal. However, based on the localization study [10], the protein localizes to both the cytoplasm and nucleus. The overexpression of OsNUC1-S did not change the photosynthetic activity levels in flag leaves when plants were grown under control conditions (Figure 2), but it resulted in reduced rice seed numbers and fertility rates (Table 1). The transcriptomic analysis found increased levels of carbohydrate metabolism and sugar transmembrane transport (Figure 7). This was in agreement with the role of flag leaves as the energy source for rice grain development [18]. Interestingly, TOSL3 was enriched in linoleate 13S-lipoxygenase activity (Figure 7). Lipoxygenase is the enzyme involved in JA biosynthesis and in responding to wounding and stress [17]. The exogenous application of JA induces flag leaf senescence by regulating chlorophyll degradation, membrane deterioration, and SAG (senescence associated gene) expression levels [19]. Moreover, the overexpression of the TIFY gene could enhance the rice grain yield, possibly owing to a reduction in JA sensitivity [20]. Therefore, the increase in lipoxygenase activity in the OsNUC1-S overexpression line could increase the JA level, causing decreases in the rice grain yield and fertility rate (Table 1). Both flag and second leaves contribute to the grain-filling process [14], but flag leaves provide more than $50 \%$ of the assimilates for grain filling [21]. In a comparison between WT and transgenic lines, 
a greater $\mathrm{P}_{\mathrm{N}}$ was found only in the second leaves of the transgenic lines when grown under salt-stress conditions. This may be related to the maximization of the photosynthetic capacity of the flag leaves.

Under salt stress, a threefold reduction of $\mathrm{P}_{\mathrm{N}}$ was detected in WT, while only a 10-15\% reduction was found in the flag leaves of transgenic lines (Figure 2A). This suggested a role for OsNUC1-S in photosynthetic enhancement. The increase in photosynthetic activity was supported by the enrichment of genes involved in the photosynthetic processes, as well as in water transport and cellular homeostasis activities (Figure 8). The enrichment in nucleic acid and macromolecule metabolic processes supports a role for nucleolin that involves RNA modifications. Thus, OsNUC1-S may have a specific target for its activity, which results in greater changes in the expression levels of some genes compared with others when OsNUC1-S is overexpressed. The enrichment in carbon fixation, as well as porphyrin and chlorophyll metabolism, suggests that OsNUC1-S enhanced both the light reaction and the carbon fixation process. The increased light-saturation point (Figure 3) and carbon fixation activity (Figure 4) were consistent with the transcriptome data. Interestingly, when plants were impacted by salt, the function of OsNUC1-S changed. Both the transcriptome and physiological data indicated that this gene promoted salt tolerance through enhanced photosynthesis. Genes encoding proteins in the photosynthetic processes were strongly expressed in transgenic lines compared with WT during salt stress (Supplementary Table S1, Figure 10). Most of the up-regulated genes were located in PSI and PSII of the light reaction. Moreover, some genes in the Calvin cycle also increased, possibly causing the higher $\mathrm{P}_{\mathrm{N}}$ values in transgenic plants. The enriched genes encoding chlorophyll A-B-binding protein (Supplementary Table S1), which functions in light harvesting, were also up-regulated in transgenic plants. This supported the light-response curve results in which a higher light-saturation point occurred in transgenic plants under salt stress.

The second leaves in WT were more susceptible to salt stress than flag leaves. The former had a significant decrease in $\mathrm{F}_{\mathrm{v}} / \mathrm{F}_{\mathrm{m}}$ after 9 days of salt stress, while salt stress had no effect on flag leaves. $\mathrm{Na}^{+}$can be transferred from root to shoot, and in rice, OsHKT1;5 excludes $\mathrm{Na}^{+}$from the phloem to prevent $\mathrm{Na}^{+}$transfer to the younger leaf blades [22]. Therefore, the second leaves were affected by salt stress to a larger extent than the flag leaves. This may be the mechanism that prevents $\mathrm{Na}^{+}$toxicity from reaching the flag leaf, which has the main role in carbon fixation for grain development.

\section{Materials and Methods}

\subsection{Plant Material and Salt Treatment}

The experiment was conducted in a planting house for transgenic plants in the Botany Department, Faculty of Science, Chulalongkorn University in Thailand. Three independent transgenic rice lines expressing OsNUC1-S driven by the Ubiquitin promoter have been produced by Sripinyowanich and colleagues [12] in a "Nipponbare" rice genetic background, and the homozygous $\mathrm{T}_{3}$ generations of these transgenic lines were used in this experiment. "Nipponbare" rice seeds were obtained from the National Laboratory for Protein Engineering and Plant Genetic Engineering, Peking-Yale Joint Research Center for Plant Molecular Genetics and AgroBiotechnology, Peking University, People's Republic of China. Either wild type (WT) or transgenic seeds were germinated for 7 days. Then, seedlings were transferred to pots containing $5 \mathrm{~kg}$ of soil. When plants were at the booting stage, $150 \mathrm{mM} \mathrm{NaCl}$ solution was added to cause salt stress at $8-10 \mathrm{ds} \cdot \mathrm{m}^{-1}$. All photosynthetic parameters were measured after 9 days salt treatment using a Gas Analysis System (LI-COR, LI-6400, USA) with a $1200 \mu \mathrm{mol} \cdot \mathrm{m}^{-2} \cdot \mathrm{s}^{-1}$ light intensity and $380 \mu \mathrm{mol} \mathrm{mol}{ }^{-1}$ carbon dioxide $\left(\mathrm{CO}_{2}\right)$ concentration.

For chlorophyll fluorescence parameters, either the flag leaf or second leaf was used to determine maximum quantum yield of photosystem II (PSII) photochemistry $\left(\mathrm{F}_{\mathrm{v}} / \mathrm{F}_{\mathrm{m}}\right)$ using Pocket PEA (Hansatech Instruments, Ltd., Norfolk, UK). In total, 30 min was used for dark adaptation, and then a 1-s saturation flash was used to measure the potential maximum photochemical efficiency of PSII. 


\subsection{RNA-seq and Data Analysis}

For the transcriptomic analysis, flag leaves of WT and TOSL3, the transgenic line with OsNUC1-S overexpression, were collected 3 and 9 days after the first day of the booting stage. Total RNA was extracted using Invitrogen's Concert ${ }^{\mathrm{TM}}$ Plant RNA Reagent and then treated with DNaseI (NEB). A Dynabeads mRNA purification kit (Invitrogen, Carlsbad, CA, USA) and a KAPA Stranded mRNA-Seq Kit were used for mRNA isolation and cDNA libraries' preparation, respectively. Fragment sizes of $\sim 300 \mathrm{bp}$ were selected and connected with adaptors. Then, the fragments were enriched by PCR for 12 cycles. All libraries were sequenced using the Genome Analyzer (Illumina HiSeq4000, San Diego, CA, USA). Adaptors were subsequently removed from all short-sequence reads before grouping, following the protocol of Missirian et al. [23]. All the sequences were aligned and mapped to the rice genome, and then, the differentially expressed genes (DEGs) were identified using the DESeq program [24]. The genes showing the differential expression were selected to validate with quantitative RT-PCR. LOC_Os01g58470, LOC_Os01g64960, LOC_Os03g39610, and LOC_Os04g33830 predicted to localize in plastids were selected. The primers for detection of the gene expression are shown in Table 2. OsEF-1 $\propto$ gene expression was used as an internal control. For q-RT-PCR, briefly, $1 \mu \mathrm{L}$ of RNA extraction from either WT's or transgenic rice's flag leaves was used to synthesize the cDNA with an AccuPower ${ }^{\circledR}$ RT PreMix (BIONEER, Oakland, CA, USA). Gene expression of the target genes was detected by quantitative PCR using Luna ${ }^{\circledR}$ Universal qPCR Master MiX (BioLabs, San Diego, CA, USA). The thermal cycle was performed at $95^{\circ} \mathrm{C}$ for $60 \mathrm{~s}$, then 40 cycles of $95^{\circ} \mathrm{C}$ for $15 \mathrm{~s}, 58.5^{\circ} \mathrm{C}$ for $30 \mathrm{~s}$, followed by $95^{\circ} \mathrm{C}$ for $30 \mathrm{~s}$, and the extension was done at $70^{\circ} \mathrm{C}$ for $5 \mathrm{~s}$. The relative expression of interesting genes was calculated using the Pfaffl method [25] with the formula:

$$
\text { Ratio }=\left(\mathrm{E}_{\text {target }}\right) \Delta \mathrm{CPtarget}(\text { control-sample }) /\left(\mathrm{E}_{\text {ref }}\right) \Delta \mathrm{CPref}(\text { control-sample })
$$

Table 2. Primers for gene expression detection.

\begin{tabular}{cccc}
\hline Gene & Primer & Sequence $\left(\mathbf{5}^{\prime}-\mathbf{3}^{\prime}\right)$ & Tm $\left({ }^{\circ} \mathbf{C}\right)$ \\
\hline \multirow{2}{*}{ OsEF-1 $\propto$} & EF-1 $\propto-\mathrm{F}$ & ATGGTTGTGGAGACCTTC & 53.7 \\
& EF-1 $\propto-\mathrm{R}$ & ATGGTTGTGGAGACCTTC & 58.2 \\
\hline \multirow{2}{*}{ LOC_Os01g58470 } & Os01g58470-F & AGGCATTGATCCTGAGACAG & 54.3 \\
& Os01g58470-R & AGAGCAGAATATCCCACTGC & 54.4 \\
\hline \multirow{2}{*}{ LOC_Os01g64960 } & Os01g64960-F & GCATCGCCTTCTCCATCA & 57.1 \\
& Os01g64960-R & GAAGACGACGTTGAAGAGGA & 57.3 \\
\hline \multirow{2}{*}{ LOC_Os03g39610 } & Os03g39610-F & GGAGGCGGTGTGGTTCAAGG & 61.0 \\
& Os03g39610-R & GCGGTAGCCCTCGACGAATC & 60.3 \\
\hline \multirow{2}{*}{ LOC_Os04g3383 } & Os04g33830-F & CCGTTCTGGCTGTGGTT & 55.4 \\
& Os04g33830-R & CGTCCGTACAGTCAAGCTAA & 54.3 \\
\hline
\end{tabular}

\subsection{Gene Ontology (GO) Term Analysis}

Genes that had a $p$-value $<0.5$ and $\log _{2}$ fold change less than -1 or more than 1 were classified into GO terms using the ClueGO tool [26]. They were analyzed into three GO terms, cellular compartment, biological process, and molecular function, and subjected to a KEGG [27] pathway analysis.

\subsection{Pigment Extraction and Quantification}

Chlorophyll $a$, chlorophyll $b$, and total carotenoid contents were studied according to the method of Lichtenthaler [28]. Briefly, $50 \mathrm{mg}$ fresh weight of either flag leaves or second leaves were extracted with $10 \mathrm{~mL}$ of $80 \%$ acetone and then incubated in the dark for $24 \mathrm{~h}$ at room temperature. Pigment extracts were measured at 470, 646.8, and $663.2 \mathrm{~nm}$ using a spectrophotometer (Agilent Technology, Santa Clara, CA, USA). 


\subsection{Yield Collection}

After a 9 days salt-stress treatment, plants were recovered by the addition of water until soil salinity was below $2 \mathrm{ds} \cdot \mathrm{m}^{-1}$. Seeds were harvested when they were fully developed and then desiccated. The numbers of panicles per plant and seeds per panicle, as well as the fertility rates (\%), were determined.

\subsection{Statistical Analysis}

A randomized complete block design with four replications was used for the experimental plots. Analysis of variance was performed to detect the differences among means and a Tukey's range test was used to detect significant differences between each mean at $p$-value $<0.05$ using SPSS 21.0 statistical software. All the results are presented as mean \pm standard error of the mean.

\section{Conclusions}

Based on the experimental results, a role of OsNUC1-S in the salt tolerance of rice during the reproductive stage was suggested to be due to the enhancement of photosynthetic processes in both flag and second leaves through the modification of gene expression levels in water transport, photosynthesis, cellular homeostasis, and carotenoid biosynthesis. These could help maintain the grain yield after a salt stress (Figure 11).

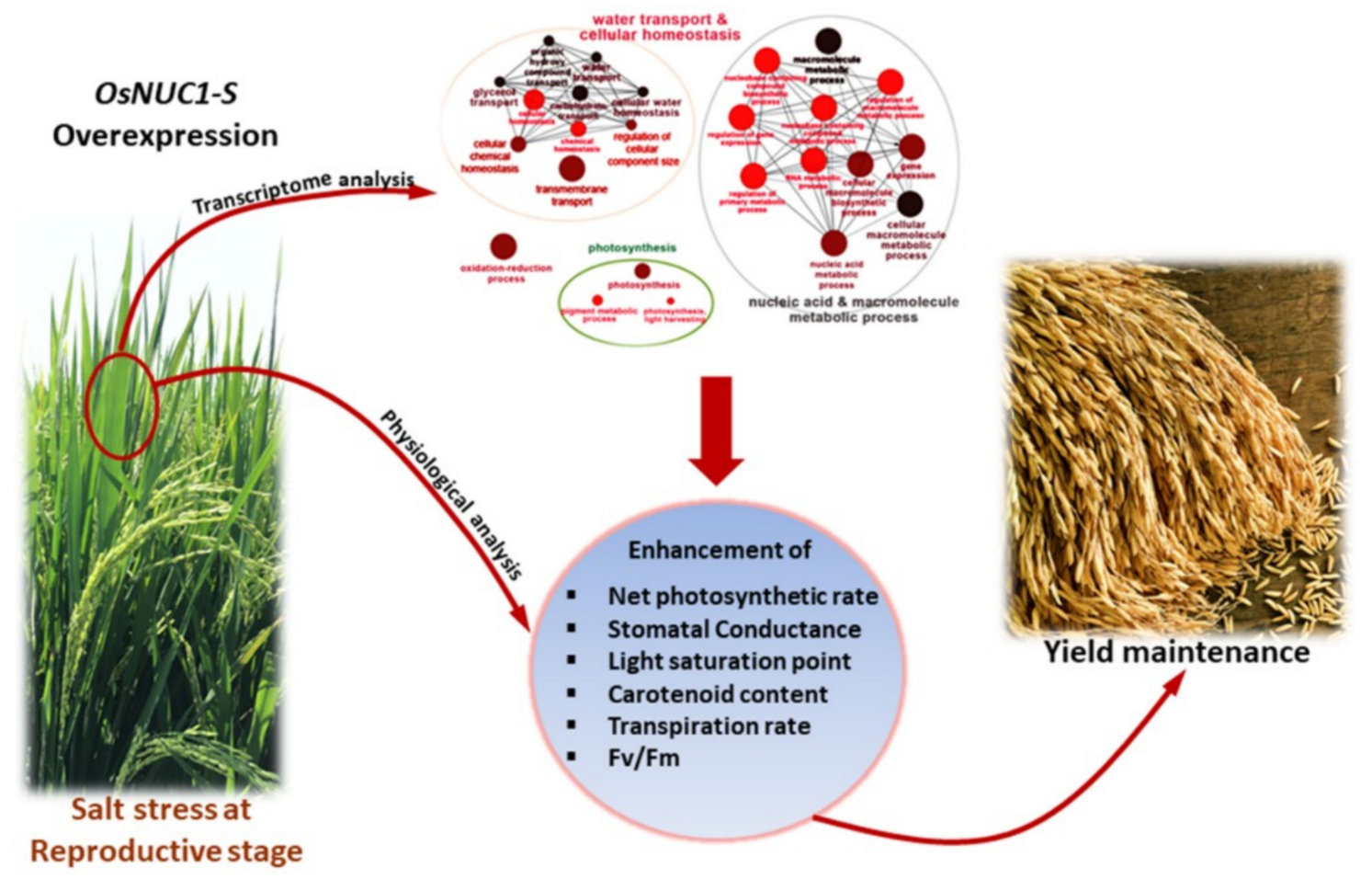

Figure 11. The scheme summarized the role of OsNUC1-S overexpression contributing to salt tolerance in rice.

Supplementary Materials: The following are available online at http:/ /www.mdpi.com/1422-0067/19/12/3936/s1.

Author Contributions: Conceptualization, S.C. and L.C.; methodology, S.C., T.B. and L.C.; software, L.C. and T.U.; validation, C.B. and S.S.; formal analysis, C.B. and S.C.; investigation, C.B.; resources, S.S.; data curation, S.C. and T.B.; writing-original draft preparation, C.B.; writing-review and editing, S.C., T.B. and L.C.; supervision, S.C., L.C. and T.B.; project administration, S.C.; funding acquisition, S.C. 
Funding: This research was supported by the Ratchadaphiseksomphot Endowment Fund (2015-16), Chulalongkorn University (grant numbers RES560530061-FW, CU-58-012-FW) and Sci-SuperIV fund from Faculty of Science, Chulalongkorn University. C.B. was supported by the Overseas Research Experience Scholarship (ORES) for Graduate Students from the Graduate School and the Faculty of Science, Chulalongkorn University and Science Achievement Scholarship of Thailand.

Acknowledgments: We thank Lesley Benyon from Edanz Group (www.edanzediting.com/ac) for editing a draft of this manuscript.

Conflicts of Interest: The authors declare no conflict of interest.

\begin{tabular}{ll}
\multicolumn{2}{l}{ Abbreviations } \\
$\mathrm{Ci}$ & intercellular $\mathrm{CO}_{2}$ concentration \\
$\mathrm{F}_{\mathrm{v}} / \mathrm{F}_{\mathrm{m}}$ & intercellular $\mathrm{CO}_{2}$ concentration \\
$\mathrm{g}_{\mathrm{s}}$ & stomatal conductance \\
OsNUC1 & rice NUCLEOLIN1 \\
$\mathrm{P}_{\mathrm{N}}$ & net photosynthesis rate \\
WT & wild type
\end{tabular}

\section{References}

1. Fageria, N. Yield physiology of rice. J. Plant Nutr. 2007, 30, 843-879. [CrossRef]

2. Hakim, M.; Juraimi, A.; Begum, M.; Hanafi, M.; Ismail, M.R.; Selamat, A. Effect of salt stress on germination and early seedling growth of rice (Oryza sativa L.). Afr. J. Biotechnol. 2010, 9, 1911-1918.

3. Bethke, P.C.; Drew, M.C. Stomatal and nonstomatal components to inhibition of photosynthesis in leaves of Capsicum annuum during progressive exposure to $\mathrm{NaCl}$ salinity. Plant Physiol. 1992, 99, 219-226. [CrossRef] [PubMed]

4. Reddy, M.; Vora, A. Changes in pigment composition, Hill reaction activity and saccharides metabolism in Bajra (Pennisetum typhoides S \& H) leaves under NaCl salinity. Photosynthetica 1986, 20, 50-55.

5. Petrov, V.; Hille, J.; Mueller-Roeber, B.; Gechev, T.S. ROS-mediated abiotic stress-induced programmed cell death in plants. Front. Plant Sci. 2015, 66, 69. [CrossRef] [PubMed]

6. Lutts, S.; Kinet, J.; Bouharmont, J. Changes in plant response to $\mathrm{NaCl}$ during development of rice (Oryza sativa L.) varieties differing in salinity resistance. J. Exp. Bot. 1995, 46, 1843-1852. [CrossRef]

7. Touch, S.; Pipatpongsa, T.; Takeda, T.; Takemura, J. The relationships between electrical conductivity of soil and reflectance of canopy, grain, and leaf of rice in northeastern Thailand. Int. J. Remote Sens. 2015, 36, 1136-1166.

8. Zhang, J.; Lin, Y.J.; Zhu, L.F.; Yu, S.M.; Sanjoy, K.K.; Jin, Q.Y. Effects of 1-methylcyclopropene on function of flag leaf and development of superior and inferior spikelets in rice cultivars differing in panicle types. Field Crops Res. 2015, 177, 64-74. [CrossRef]

9. Tajrishi, M.M.; Tuteja, R.; Tuteja, N. Nucleolin: The most abundant multifunctional phosphoprotein of nucleolus. Commun. Integr. Biol. 2011, 4, 267-275. [CrossRef]

10. Petricka, J.J.; Nelson, T.M. Arabidopsis nucleolin affects plant development and patterning. Plant Physiol. 2007, 144, 173-186. [CrossRef]

11. Reichler, S.A.; Balk, J.; Brown, M.E.; Woodruff, K.; Clark, G.B.; Roux, S.J. Light differentially regulates cell division and the mRNA abundance of pea nucleolin during de-etiolation. Plant Physiol. 2001, 125, 339-350. [CrossRef] [PubMed]

12. Sripinyowanich, S.; Chamnanmanoontham, N.; Udomchalothorn, T.; Maneeprasopsuk, S.; Santawee, P.; Buaboocha, T.; Qu, L.-J.; Gu, H.; Chadchawan, S. Overexpression of a partial fragment of the salt-responsive gene OsNUC1 enhances salt adaptation in transgenic Arabidopsis thaliana and rice (Oryza sativa L.) during salt stress. Plant Sci. 2013, 213, 67-78. [CrossRef] [PubMed]

13. Udomchalothorn, T.; Plaimas, K.; Sripinyowanich, S.; Boonchai, C.; Kojonna, T.; Chutimanukul, P.; Comai, L.; Buaboocha, T.; Chadchawan, S. OsNucleolin1-L expression in Arabidopsis enhances photosynthesis via transcriptome modification under salt stress conditions. Plant Cell Physiol. 2017, 58, 717-734. [CrossRef] [PubMed] 
14. Lee, S.; Jeong, H.; Lee, S.; Lee, J.; Kim, S.-J.; Park, J.-W.; Woo, H.R.; Lim, P.O.; An, G.; Nam, H.G. Molecular bases for differential aging programs between flag and second leaves during grain-filling in rice. Sci. Rep. 2017, 7, 8792. [CrossRef]

15. Junghans, T.G.; De Almeida-Oliveira, M.G.; Moreira, M.A. Lipoxygenase activities during development of root and nodule of soybean. Pesqui. Agropecu. Bras. 2004, 39, 625-630. [CrossRef]

16. Lenglet, A.; Jaślan, D.; Toyota, M.; Mueller, M.; Müller, T.; Schönknecht, G.; Marten, I.; Gilroy, S.; Hedrich, R.; Farmer, E.E. Control of basal jasmonate signalling and defence through modulation of intracellular cation flux capacity. New Phytol. 2017, 216, 1161-1169. [CrossRef]

17. Brodhun, F.; Cristobal-Sarramian, A.; Zabel, S.; Newie, J.; Hamberg, M.; Feussner, I. An iron 13S-lipoxygenase with an $\alpha$-linolenic acid specific hydroperoxidase activity from Fusarium oxysporum. PLoS ONE 2013, 8, e64919. [CrossRef]

18. Kholupenko, I.; Voronkova, N.; Burundukova, O.; Zhemchugova, V. Demand for assimilates determines the productivity of intensive and extensive rice crops in Primorskii krai. Russ. J. Plant Physiol. 2003, 50, 112-118. [CrossRef]

19. Liu, L.; Li, H.; Zeng, H.; Cai, Q.; Zhou, X.; Yin, C. Exogenous jasmonic acid and cytokinin antagonistically regulate rice flag leaf senescence by mediating chlorophyll degradation, membrane deterioration, and senescence-associated genes expression. J. Plant Growth Regul. 2016, 35, 366-376. [CrossRef]

20. Hakata, M.; Muramatsu, M.; Nakamura, H.; Hara, N.; Kishimoto, M.; Iida-Okada, K.; Kajikawa, M.; Imai-Toki, N.; Toki, S.; Nagamura, Y. Overexpression of TIFY genes promotes plant growth in rice through jasmonate signaling. Biosci. Biotechnol. Biochem. 2017, 81, 906-913. [CrossRef]

21. Li, Z.; Pinson, S.R.; Stansel, J.W.; Paterson, A.H. Genetic dissection of the source-sink relationship affecting fecundity and yield in rice shape (Oryza sativa L.). Mol. Breed. 1998, 4, 419-426. [CrossRef]

22. Kobayashi, N.I.; Yamaji, N.; Yamamoto, H.; Okubo, K.; Ueno, H.; Costa, A.; Tanoi, K.; Matsumura, H.; Fujii-Kashino, M.; Horiuchi, T.; et al. OsHKT1;5 mediates $\mathrm{Na}^{+}$exclusion in the vasculature to protect leaf blades and reproductive tissues from salt toxicity in rice. Plant J. 2017, 91, 657-670. [CrossRef] [PubMed]

23. Missirian, V.; Henry, I.; Comai, L.; Filkov, V. POPE: Pipeline of parentally-biased expression. In Proceedings of the ISBRA: 2012 Bioinformatics Research and Applications, Dallas, TX, USA, 21-23 May 2012; pp. 177-188.

24. Anders, S.; Huber, W. Differential expression analysis for sequence count data. Genome Biol. 2010, 11, R106. [CrossRef] [PubMed]

25. Pfaffl, M.W. A new mathematical model for relative quantification in real-time RT-PCR. Nucleic Acids Res. 2001, 29, e45. [CrossRef] [PubMed]

26. Bindea, G.; Mlecnik, B.; Hackl, H.; Charoentong, P.; Tosolini, M.; Kirilovsky, A.; Fridman, W.-H.; Pagès, F.; Trajanoski, Z.; Galon, J. ClueGO: A Cytoscape plug-in to decipher functionally grouped gene ontology and pathway annotation networks. Bioinformatics 2009, 25, 1091-1093. [CrossRef] [PubMed]

27. Kanehisa, M.; Goto, S. KEGG: Kyoto encyclopedia of genes and genomes. Nucleic Acids Res. 2000, $28,27-30$. [CrossRef] [PubMed]

28. Lichtenthaler, H.K. Chlorophylls and carotenoids: Pigments of photosynthetic biomembranes. Methods Enzymol. 1987, 148, 350-380.

(C) 2018 by the authors. Licensee MDPI, Basel, Switzerland. This article is an open access article distributed under the terms and conditions of the Creative Commons Attribution (CC BY) license (http://creativecommons.org/licenses/by/4.0/). 